\title{
Long-term Exposure to Predation Threat Can Modulate the Expression of Sexually Selected Traits in Male Guppy (Poecilia reticulata)
}

\author{
Md. Moshiur Rahman ${ }^{1}$, Prianka Biswas ${ }^{1}$, Sazzad Hossain ${ }^{1}$, Sheikh Mustafizur \\ Rahman $^{1,2, *}{ }^{-}$, Ahmed Saud Alsaqufi ${ }^{3}$, Md. Mahmud-Al-Hasan ${ }^{1,4}$, Prema Hazra ${ }^{1}$, \\ Md. Mostafizur Rahman ${ }^{5}$, Md. Asadujjaman ${ }^{6}$
}

\author{
${ }^{1}$ Khulna University, Fisheries and Marine Resource Technology Discipline, Khulna-9208, Bangladesh. \\ ${ }^{2}$ King Faisal University, Fish Resources Research Center, Hofuf-420, Al-Ahsa, Kingdom of Saudi Arabia. \\ ${ }^{3}$ King Faisal University, Animal and Aquaculture Production Department, College of Agriculture and Food Sciences, Hofuf-420, Al- \\ Ahsa, Kingdom of Saudi Arabia. \\ ${ }^{4}$ University of Bremen, International Studies in Aquatic Tropical Ecology, 28359 Bremen, Germany. \\ ${ }^{5}$ Bangladesh University of Professionals, Disaster and Human Security Management, Dhaka, Bangladesh. \\ ${ }^{6}$ Khulna Agricultural University, Fisheries and Ocean Sciences, Khulna, Bangladesh.
}

\section{How to cite}

Rahman, M.M., Biswas, P., Hossain, S., Rahman, S.M., Alsaqufi, A.S., Mahmud-Al-Hasan, M., Hazra, P., Rahman, M.M., Asadujjaman, M. (2021). Long-term Exposure to Predation Threat Can Modulate the Expression of Sexually Selected Traits in Male Guppy (Poecilia reticulata). Turkish Journal of Fisheries and Aquatic Sciences, 21, 357-364. https://doi.org/10.4194/1303-2712-v21_7_05

\section{Article History}

Received 08 January 2021

Accepted 09 April 2021

First Online 27 April 2021

Corresponding Author

Tel.: +8801406664905

E-mail: srahman@kfu.edu.sa

\section{Keywords}

Environment

Predator

Courtship

Growth

Ornament

\begin{abstract}
The expression of sexual traits can be affected by different environmental factors among which predation may be particularly important life-history traits. This study investigated the effects of predation risk on courtship behavior, growth and sexual color patterns in male guppy (Poecilia reticulata). In the study, juvenile male guppies were randomly assigned to two treatments, namely T1 (predation threat) and T2 (no predation threat). The courtship performances were visually observed and recorded, while color patterns and morphological traits were measured by using the ImageJ software from the captured photos. The courtship behavioral trials revealed that predation threatened males performed significantly lower number of sigmoid displays than those of no-predation group. Further, the predation scared group had significantly shorter standard length, body area and a reduced number and area of orange spots than their counter group. However, the predation threat did not affect significantly the gonopodial thrusts, and black and iridescent color components (spot number and area). The reduction of costly traits (e.g. behavior, color patterns and body size) is common anti-predator response which presumably reduces predation risks. Male guppies are probably using this form of defence in response to the increased predation risk. The overall result suggests that growth and sexually selected trait expression are sensitive to predation risk and thereby aid in our understanding to predict the evolution of phenotypic variation in natural systems.
\end{abstract}

\section{Introduction}

Predation can play a pivotal role in shaping various life-history traits and anti-predatory responses in prey species (Šmejkal et al., 2017). Typically, predation risk varies unpredictably in space and time (Blanchard et al., 2018) and create variation and uncertainty in predation intensity (Brown et al., 2013). Based on the type of predator and the level of predation, prey modulate some of their phenotypic traits in response to the perceived predation risk to minimize the associated fitness costs (Schmitz, 2017). Evidences showed that prey usually adapt their anti-predatory response depending upon the magnitude and strength of 
predation risks (Schmitz, 2017). For examples, in many cases prey change their behavior to avoid predators, modulate their physiological activities to generate energy for escaping predation (Van Dievel et al., 2016), and change their morphological characteristics to adapt to predation risks (Eklöv \& Svanbäck, 2006; Van Dievel et al., 2016).

Evidence that predation threat can influence the expression of various phenotypic traits is especially abundant in fish species (Eklöv \& Svanbäck, 2006; Endler, 1978; Grégoir et al., 2018; Tang et al., 2017). For instances, Reznick and Endler (Reznick \& Endler, 1982) showed that body size of mature male guppies (Poecilia reticulata) varied based on the level of predation intensity in which males from the highly predation risk sites (where the main predator Crenicichla was abundant) were significantly smaller in size compared to medium (main predator Rivulus, which predates mainly on juveniles) and low predation sites (only Aequidens, a non-pradator species was present). In another study, Forsgren and Magnhagen (Magnhagen \& Forsgren, 1993) found that males of sand gobies (Pomatoschistus minutus) significantly decreased their total number of courtship activity in the presence of a predator (cod, Gadus morhua), while females did not alter their level of activity at this circumstance. In guppy, although males' bright orange color pattern is favored by females during courtship (Godin \& Dugatkin, 1996), males showed a reduced size of orange spots when exposed to predation cues during development (Ruell et al., 2013). Similarly, predation-induced stresses can influence survival, feeding, behaviour, skin pigmentation, growth and reproduction, in several fish species (Grégoir et al., 2018; Raby et al., 2014; Svanbäck et al., 2017). In a more limited number of studies the effect of predation risk on the plasticity in the expression of traits that may influence male reproductive success has been studied simultaneously (Reznick \& Endler, 1982). The present study was carried out under laboratory condition to explore the impacts of predation threats on the expression of the main sexually selected phenotypic traits that affect male mating success, namely courtship behavior, growth and color patterns, in male guppy ( $P$. reticulata) which is a popular model fish species.

Guppies are small poeciliid fish native to the northeast of South America but introduced worldwide as they are highly adaptable and thrive in many different environmental and ecological conditions. Males are typically smaller than females and exhibit highly complex color patterns such as orange, iridescent, and black spots (Houde, 1997). Males exhibit their conditiondependent color patterns during their courtship behavior towards females, which prefer more active and brightly colored males (Houde, 1997). Studies also demonstrated that female guppies have a mating preference for large males (Auld et al., 2017). At the same time, it is known that large, colorful and more active males are exposed to a higher risk of predation. Thus, male guppies color patterns, courtship behavior and body size are deemed as appropriate sexual traits which have been investigated in this study, to test whether predators' presence (visual cue) and smell (olfactory cue) during development could modulate the expression of these sexually selected traits using this model species.

\section{Material and Methods}

\section{Fish Collection}

Around 300 juveniles of guppy were collected from the natural sources and transported to the 'Wet Fish Laboratory' of Fisheries and Marine Resource Technology (FMRT) Discipline, Khulna University, Bangladesh. Then they were reared in a $50 \mathrm{~cm} \times 29 \mathrm{~cm} \times 30 \mathrm{~cm}$ sized large glass aquarium and conditioned up to one week before starting the experiment.

\section{Fish Rearing}

In total 72 almost same sized male juveniles (mean \pm SE of standard length: $12.6 \pm 0.22$; ANOVA: $\mathrm{F}_{1,70}=2.51, \mathrm{P}=0.12$ ) and 30 mature females (collected latter) were selected for this experiment rearing them in the closed aquarium system by observing their gonopodium and/or color patches (followed previous studies: Rahman et al., 2013; 2014; 2020). The study was carried out up to three months having two treatments (i.e. T1 and T2) with three replications in each treatment, and each replication contained 12 males. In $\mathrm{T} 1$, males were reared under predation threat, whereas males did not have any predation threat in T2 (Figure 1). Every replicate had almost a same sized spotted snakehead Channa punctata $(n=3$, mean \pm SE of total length: $11.96 \pm 0.33 \mathrm{~cm}$ ) and Asian stinging catfish Heteropneustes fossilis ( $n=3$, mean \pm SE of total length: $10.11 \pm 0.29 \mathrm{~cm}$ ) as predators in this study as they are the major predators in the wild in Bangladesh. In the experiment, each tank was divided into three chambers (each chamber: $20 \mathrm{~cm} \times 30 \mathrm{~cm} \times 30 \mathrm{~cm}$ ) with the transparent plastic sheet. The experiment was designed in such a way that the experimental male guppies were stocked in the middle chamber, while two predators were kept in the first chamber in which the plastic divider possessed some tiny pores at the bottom, and 12 females were reared in the third chamber having no pores on the plastic divider (Figure 1A). The transparent plastic divider allowed males to watch the predators and the tiny pores permitted water exchange to get chemical cues between prey and predators. Thus, the T1 experimental males could have the chance to watch as well as get smell of predators, while T2 group males were free from these cues. The visual stimuli from females of adjacent chamber ensured that the focal males were able to perceive potential mating opportunities during the experimental period. The experimental males, females and predators were fed 
Treatment

A. Experimental design

T1

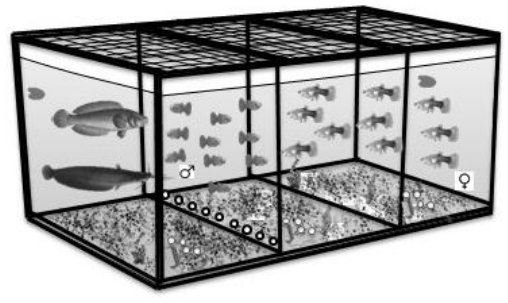

T2

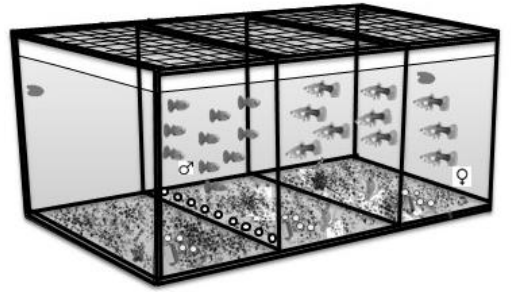

B. Courtship trial
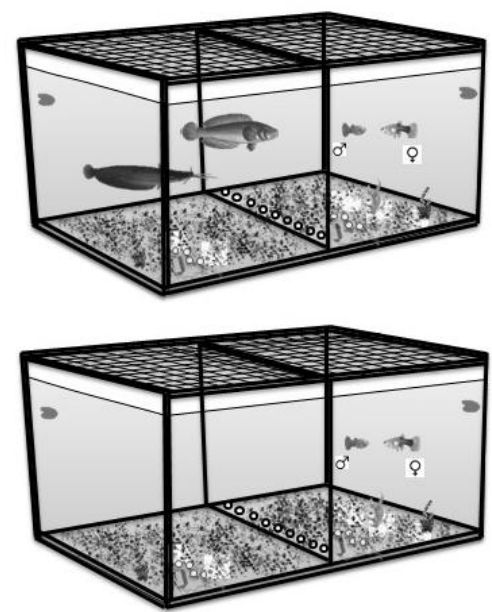

Figure 1. (A) The experimental design and (B) the courtship trial according to different treatments. Here, $\mathrm{T} 1$ is the treatment in which males faced the predation threat, while $\mathrm{T} 2$ is another treatment where males did not face these predators.

once 6 days per week at a satiation level with a commercial diet of Mega feed throughout the experimental period. Water quality parameters including temperature, $\mathrm{pH}$ and dissolved oxygen (DO) were monitored daily although all aquariums were kept in a temperature-controlled room having continuous aeration. About half of the water from each aquarium was removed by siphoning every alternative day to clean the faces and uneaten food. Adhered dirt inside the aquarium walls were also cleaned once a week.

\section{Courtship Behavior}

Courtship behavioral trials took place between 07.00 and 12.00 to correspond with the peak of sexual activity in this species (Houde, 1997). First, a mature female from the newly collected stock was transferred in a separate behavioral aquarium and allowed to settle around 10 minutes (followed previous studies: Rahman et al., 2013; 2020). For T1 group, predators were placed in a separate adjacent chamber $(30 \mathrm{~cm} \times 30 \mathrm{~cm} \times 30 \mathrm{~cm})$, while no predators were placed in case of $\mathrm{T} 2$ group (Figure 1B). Then a single experimental male from a treatment was placed in the female's chamber $(30 \mathrm{~cm} \times 30 \mathrm{~cm} \times 30 \mathrm{~cm})$ and allowed to settle for at least 5 minutes or until it showed sexual interest to the female (i.e., following the female or engaging in courtship). For each 10 minutes trial, the male mating behaviors were recorded as the number of sigmoid displays (males arch their body in a characteristic shaped posture and quiver), gonopodial thrusts (forced mating attempts in which males approach females from behind and attempt copulations without prior courtship or female solicitation), and the time (in seconds) spent by the male courting or chasing the female (a measure of the male's overall sexual interest in the female, hereafter "sexual interest") (Houde, 1997). After each trial, the male and female were transferred to separate reserve aquarium and once all trails were finished, males were returned to their own treatment tank and kept for seven days before being used for the measurements of body size and color patterns.

\section{Body Size Measurement}

Each male was anesthetized for a while individually using tricaine methanesulfonate (MS222). Then a clear photograph was taken under a standard lighting condition by placing the fish on a laminated graph paper. A digital camera (Canon DS126621) was ready with a stand to take the photograph from a fixed distance of $30 \mathrm{~cm}$. Each image included a unique code so that subsequent analyses of male traits were performed blind of treatment. Finally, standard length (the distance in $\mathrm{mm}$ from the fish snout to the tip of its caudal peduncle), body area (the area [in $\mathrm{mm} 2$ ] of the body excluding all fins and tail) were measured from the captured images using the ImageJ software (http://rsbweb.nih.gov/ij/).

\section{Male Body Coloration}

Skin pigmentation of each male $(\mathrm{N}=72)$ was also measured from the same captured images using the ImageJ software. The total number of black, orange, and iridescent spots was recorded and the total area of these color spots on the left side of the body was measured, including the area of carotenoid and pteridine pigments and structural colors.

\section{Statistical Analyses}

All analyses were performed using ' $R$ ' version 3.5.2. Descriptive statistics (means and SEs) were calculated using the 'pysch' package. The Shapiro-Wilk test of normality and the Levene's tests for homogeneity of variance were done with the 'onewaytests' package. 
Appropriate transformation method was applied for non-normal data.

The univariate analyses of variance (ANOVA) model was selected using the 'car' package to explore the effects of treatment (i.e. predation threat) on (i) fish body size (e.g. standard length and body area) and (ii) sexual color area (different color patches). The count data (e.g. sigmoid displays, gonopodial thrusts, sexual interest and sexual color spot number) were analysed with a generalized linear mixed model (GLMM) using the 'glmmADMB' package. In GLMM model, the 'treatment' was entered as a fixed effect allowing or not allowing zero-inflation (based on having many zeros or not) with negative binomial distribution. The negative binomial distribution was used to approximate over dispersion. The 'ggplot2' package was used to show all the significant variations between two treatments graphically.

\section{Results and Discussion}

The statistical analyses revealed significant effects of perceived predation threat on a courtship behavioral trait (e.g. sigmoid displays), body size (i.e. standard length and body area) and few color patterns (e.g. orange spot number and area), while no profound effect was found on some other sexually selected traits (e.g. gonopodial thrusts, sexual interest, black and iridescent color patterns).

In courtship behavioral trial, we found that males exposed to predation threat (T1) performed significantly lower number of sigmoid displays (mean $\pm S E$ : 0.79 \pm 0.30 ; GLMM: $\mathrm{Z}_{1,68}=2.10, \mathrm{P}<0.05$ and Figure 2 ) than those did not see the predators (T2) at any time (mean \pm SE: $2.76 \pm 0.55$ ) during the experimental period. The study found no significant effect of predation threat on gonopodial thrusts between two rival groups (T1: $0.32 \pm 0.12$ and T2: $0.09 \pm 0.05$; GLMM: $Z_{1,68}=1.76$ and $\mathrm{P}=0.08)$. Similarly, the analysis of sexual interest records revealed no significant variation between the two treatments ( $\mathrm{T} 1: 230.26 \pm 42.12$ and $\mathrm{T} 2: 112.85 \pm 27.69$; GLMM: $Z_{1,68}=1.38$ and $\left.P=0.17\right)$. These decrease of sigmoid displays in mating activity during courtship trials in the presence of predators is in accordance with studies in the same (Endler, 1987) and some other species with conspicuous courtship displays (Koga et al., 1998).

The study also found that the experimental male guppies had significantly shorter standard length when exposed to predation threat (mean \pm SE: 15.61 \pm 0.28 ; ANOVA: $F_{1,68}=10.38, P<0.01$ and Figure $3 A$ ) and smaller body area (mean $\pm S E$ : $40.94 \pm 0.95$; ANOVA: $F_{1,68}=13.09$, $\mathrm{P}<0.001$ and Figure $3 \mathrm{~B}$ ) than those faced no predators (standard length: $17.10 \pm 0.37$ and body area: $51.80 \pm 1.61)$. There are intriguing parallels to these findings which demonstrated that predation risk can significantly reduce body size of scared prey (Reznick \& Endler, 1982).
The present study also consistently revealed that predation cues can significantly reduce the expression of color patterns in the threatened fish which corroborates the findings of some other studies (Endler, 1978; Ruell et al., 2013). The study found that males exposed to the predation threat (T1) had a significantly lower number of orange spots (mean \pm SE: 2.56 \pm 0.18 ; GLMM: $\mathrm{Z}_{1,68}=13.16, \mathrm{P}<0.001$ and Figure $4 \mathrm{~A}$ ) and reduced orange area (mean \pm SE: $2.20 \pm 0.12$; ANOVA: $F_{1,68}=13.06, P<0.001$ and Figure $4 \mathrm{~B}$ ) compared to those did not face this risk (orange spots: $3.41 \pm 0.19$ and orange area: $3.23 \pm 0.24$ ). The analyses revealed no significant differences between two treatment groups in terms of iridescent spot number (T1: $1.61 \pm 0.28$ and T2: $2.85 \pm 0.22 ;$ GLMM: $\mathrm{Z}_{1,68}=1.19$ and $\mathrm{P}=0.23$ ) and area (T1: $2.68 \pm 0.30$ and $\mathrm{T} 2$ : 3.23 \pm 0.24 ; ANOVA: $F_{1,68}=0.79$ and $P=0.38$ ), black spot number (T1: $1.65 \pm 0.16$ and T2: $1.91 \pm 0.11$; GLMM: $\mathrm{Z}_{1,68}=0.82$ and $\left.\mathrm{P}=0.41\right)$ and area (T1: $1.58 \pm 0.10$ and $\mathrm{T} 2$ : 1.49 \pm 0.13 ; ANOVA: $F_{1,68}=0.09$ and $\left.P=0.77\right)$.

Sigmoid displays, body size and bright color patterns are conspicuous sexual traits and apparently expression of these easily visible sexual traits may increase the risk of predation (Godin \& McDonough, 2003). To avoid the risk of predation, animals experience high predation threats tend to be less colorful (i.e. more cryptic) than others having weaker predation intensity (Endler, 1978; Reznick \& Endler, 1982). Moreover, many animals modulate their exaggerated sexual behaviors to reduce the susceptibility to high predation risk (Pascual et al., 2014). The larger the body size, the greater the chance to be visible to the predators and therefore, logically many animals compensate by reducing their body size in order to avoid high predation risk (Reznick \& Endler, 1982). These could be the plausible explanations that the predation threatened group in the present study were less colorful, performed lower number of sigmoid displays and reduced body size to avoid the susceptibility of easy predation.

Most of the hypotheses state that 'predation threat' is an environmentally-induced physiological stress to the prey (Kondoh et al., 2016). Immediately after visualizing a predator or detecting its odours (chemical cues), prey sense a life-risk impending danger that stimulate changes in their behavioral responses (Plath et al., 2019) and modulations of physiological activities (Apfelbach et al., 2005). In this present study with accordance to these evidences, the significant reduction of sigmoid displays could be the response of predator feared group which were exposed for a prolonged experimental period (up to three months). Evidence revealed that the altered or reduced foraging and feeding patterns due to acute predation risk ultimately provide less energy to perform not only the energetically costly sexual behavioral trait (Pettett et al., 2017), but also affect growth (Välimäki \& Herczeg, 2012) and sexual color expression (Schmidt et al., 2012). Although we did not check the feeding activity during this study, there might be a variation in food intake between the two treatment groups which forced the 


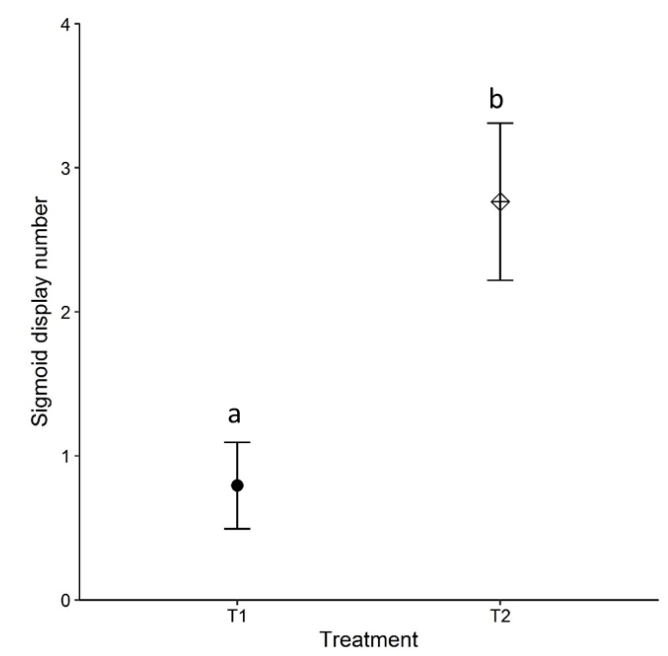

Figure 2. Sigmoid display numbers (mean $\pm \mathrm{SE}$ ) of experimental male guppy. Differences in small letters indicate significant variation between the treatments $(P<0.05)$.
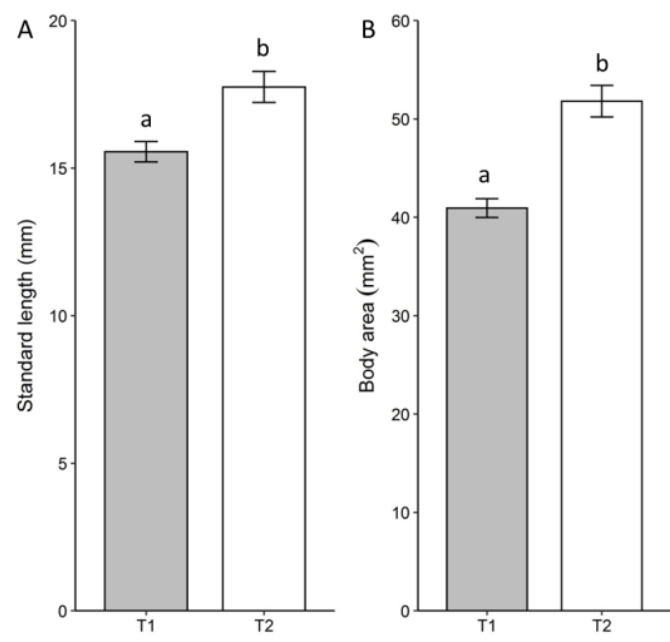

Treatment

Figure 3. The effect of predation threat on $(A)$ final standard length (mean $\pm S E$ ) and $(B)$ body area (mean $\pm S E$ ) in experimental male guppy. Differences in small letters indicate significant variation between the treatments $(P<0.05)$.
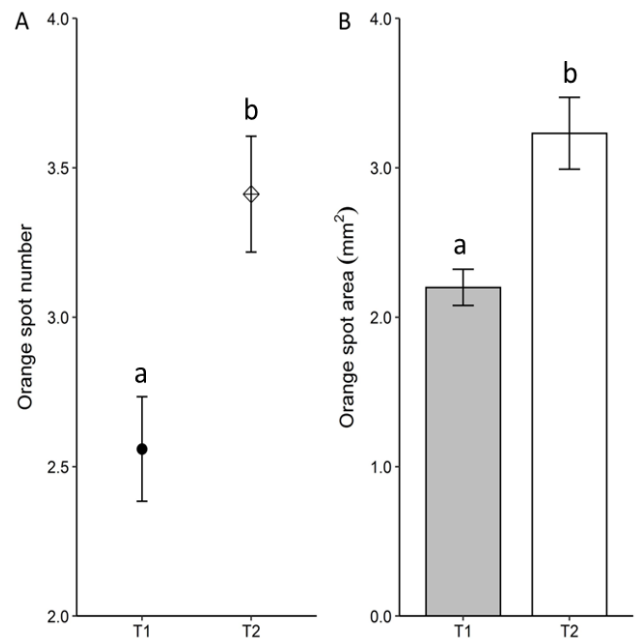

Treatment

Figure 4. The effect of predation threat on $(A)$ orange spot number (mean $\pm S E$ ) and $(B)$ orange spot area (mean $\pm S E)$ in experimental male guppy. Differences in small letters indicate significant variation between the treatments $(P<0.05)$. 
predator threatened group to intake less diet and thereby, had limited energy budget to invest expressing these energetically expensive traits.

Some studies showed that predator-induced physiological stress could impel prey to make a decision about how to balance the expression of a specific or different traits in the risky environment (Endler, 1978). For instance, studies demonstrated that organisms did not display a specific behavior in full scale or adjusted it accordingly to get benefits (i.e. survival, feeding, mating, etc.) under a risky environment through 'crypsis or mimicry' for natural selection, while they showed the same behavior elaborately in the predator free environment to compete with their rivals as 'conspicuous sexual display'(Martin et al., 2014). Evidence also demonstrated that animals could shift their conspicuous traits with other less conspicuous elements which either they did not alter or expressed exaggeratedly under the high predation cues (FowlerFinn \& Hebets, 2011). Animals need to balance the energy demand for costly honest signalling and therefore, they usually invest based on their surrounding conditions. For example, males invested maximally in all of their traits when the condition is favorable, whereas they halted this massive investment and shifted it only in certain traits during unfavorable conditions (Rahman et al., 2013). In this present study, the variation of gonopodial thrusts and time spent for sexual interest (known as visually less conspicuous and low energy required mating strategies) was not significant between two treatments which might be a reason of no reduction of these alternative mating tactics performed by the predation-present groups (Endler, 1987).

\section{Conclusion}

In summary, ecologists provided many evidences that predators can cause changes in behavior, morphology, development, and abundance of prey. The guppy has been widely used to examine behavioral and evolutionary questions relating to predation because this species exhibits great polymorphism among geographically isolated populations, and they experience different amounts of aquatic predation. They are subject to a wide range of different aquatic predators which may exert different levels of risk to their life-history traits. Our work consistently revealed that predator plays a critical role in shaping sexually selected traits in male guppies, such as sigmoid displays, body size and color patterns. However, the predators had no significant effect on expression of gonopodial thrusts, sexual interest, black and iridescent color spot number and areas. Along with similar findings, this study suggests that predation can induce stress to the prey which can limit their expression of sexually interested traits and overall production, and these information can be applied to other fields of study to manage their population diversity, conservation and commercial production.

\section{Ethical Statement}

For all trait analyses, fish were anaesthetized to render them immotile during procedures (e.g. photograph). This work was carried out under the School of Life Science of Khulna University's Animal Ethics approval (KUAEC-2017/05/13). This article does not contain any studies with human participants performed by any of the authors.

\section{Funding Information}

This study was funded by the Ministry of Science and Technology, Government of the People's Republic of Bangladesh (project no.: 39.00.0000.09.02.69.1617/BS-168/182).

\section{Author Contribution}

Md. Moshiur Rahman, Sheikh Mustafizur Rahman, Ahmed Saud Alsaqufi designed the experiment. Prianka Biswas, Sazzad Hossain, Md. Mahmud-Al-Hasan, Prema Hazra and Md. Asadujjaman conducted the experiment and collected the data. Md. Moshiur Rahman and Md. Mostafizur Rahman performed the analysis. Md. Moshiur Rahman, Sheikh Mustafizur Rahman, Ahmed Saud Alsaqufi prepared the draft manuscript, and provided extensive support and feedback on further data analysis and finalized the manuscript. All authors commented on manuscript drafts.

\section{Conflict of Interest}

The authors declare that they have no conflict of interest regarding this manuscript.

\section{Acknowledgements}

The authors thank M. Habibur Rahman, Laboratory Technician, Khulna University, Bangladesh for his great assistance with maintenance and husbandry of the studied species.

\section{References}

Apfelbach, R., Blanchard, C. D., Blanchard, R. J., Hayes, R. A., \& McGregor, I. S. (2005). The effects of predator odors in mammalian prey species: a review of field and laboratory studies. Neuroscience and biobehavioral reviews, 29(8), 1123-1144.

https://doi.org/10.1016/j.neubiorev.2005.05.005

Auld, H. L., Ramnarine, I. W., \& Godin, J.-G. J. (2017). Male mate choice in the Trinidadian guppy is influenced by the phenotype of audience sexual rivals. Behavioral ecology, 28(2), 362-372.

https://doi.org/10.1093/beheco/arw170 
Blanchard, P., Lauzeral, C., Chamaillé-Jammes, S., Brunet, C., Lec'hvien, A., Péron, G., \& Pontier, D. (2018). Coping with change in predation risk across space and time through complementary behavioral responses. BMC ecology, 18(1), 60.

https://doi.org/10.1186/s12898-018-0215-7

Brown, G. E., Ferrari, M. C., Elvidge, C. K., Ramnarine, I., \& Chivers, D. P. (2013). Phenotypically plastic neophobia: a response to variable predation risk. Proceedings of the Royal Society B: Biological Sciences, 280(1756), 20122712. https://doi.org/10.1098/rspb.2012.2712

Eklöv, P., \& Svanbäck, R. (2006). Predation risk influences adaptive morphological variation in fish populations. The American Naturalist, 167(3), 440-452. https://doi.org/10.1086/499544

Endler, J. A. (1978). A predator's view of animal color patterns. In Evolutionary biology (pp. 319-364). Springer. https://doi.org/10.1007/978-1-4615-6956-5_5

Endler, J. A. (1987). Predation, light intensity and courtship behaviour in Poecilia reticulata (Pisces: Poeciliidae). Animal Behaviour, 35(5), 1376-1385. https://doi.org/10.1016/S0003-3472(87)80010-6

Fowler-Finn, K. D., \& Hebets, E. A. (2011). The degree of response to increased predation risk corresponds to male secondary sexual traits. Behavioral ecology, 22(2), 268-275. https://doi.org/10.1093/beheco/arq197

Godin, J.-G., \& Dugatkin, L. A. (1996). Female mating preference for bold males in the guppy, Poecilia reticulata. Proceedings of the National Academy of Sciences, 93(19), 10262-10267.

https://doi.org/10.1073/pnas.93.19.10262

Godin, J.-G. J., \& McDonough, H. E. (2003). Predator preference for brightly colored males in the guppy: a viability cost for a sexually selected trait. Behavioral ecology, 14(2), 194-200.

https://doi.org/10.1093/beheco/14.2.194

Grégoir, A. F., Thoré, E. S. J., Philippe, C., Pinceel, T., Brendonck, L., \& Vanschoenwinkel, B. (2018). Squeezing out the last egg-annual fish increase reproductive efforts in response to a predation threat. Ecology and evolution, 8(13), 6390-6398.

https://doi.org/10.1002/ece3.3422

Houde, A. (1997). Sex, Color, and Mate Choice in Guppies (Vol. 71). Princeton University Press, Princeton, New Jersey.

Koga, T., Backwell, P. R., Jennions, M. D., \& Christy, J. H. (1998). Elevated predation risk changes mating behaviour and courtship in a fiddler crab. Proceedings of the Royal Society of London. Series B: Biological Sciences, 265(1404), 1385-1390. https://doi.org/10.1098/rspb.1998.0446

Kondoh, K., Lu, Z., Ye, X., Olson, D. P., Lowell, B. B., \& Buck, L. B. (2016). A specific area of olfactory cortex involved in stress hormone responses to predator odours. Nature, 532(7597), 103-106. https://doi.org/10.1038/nature17156

Magnhagen, C., \& Forsgren, E. (1993). Conflicting demands in sand gobies: predators influence reproductive behaviour. Behaviour, 126(1-2), 125-135. https://doi.org/10.1163/156853993X00371

Martin, R. A., Riesch, R., Heinen-Kay, J. L., \& Langerhans, R. B. (2014). Evolution of male coloration during a postPleistocene radiation of Bahamas mosquitofish (Gambusia hubbsi). Evolution, 68(2), 397-411. https://doi.org/10.1111/evo.12277

Pascual, J., Senar, J. C., \& Domènech, J. (2014). Plumage brightness, vigilance, escape potential, and predation risk in male and female Eurasian Siskins (Spinus spinus). The Auk: Ornithological Advances, 131(1), 61-72. https://doi.org/10.1642/AUK-13-220.1

Pettett, C. E., Johnson, P. J., Moorhouse, T. P., Hambly, C., Speakman, J. R., \& Macdonald, D. W. (2017). Daily energy expenditure in the face of predation: hedgehog energetics in rural landscapes. Journal of Experimental Biology, 220(3), 460-468.

https://doi.org/10.1242/jeb.150359

Plath, M., Liu, K., Umutoni, D., Gomes-Silva, G., Wei, J.-F., Cyubahiro, E., Chen, B.-J., \& Sommer-Trembo, C. (2019). Predator-induced changes of male and female mating preferences: innate and learned components. Current zoology, 65(3), 305-316. https://doi.org/10.1093/cz/zoz003

Raby, G. D., Packer, J. R., Danylchuk, A. J., \& Cooke, S. J. (2014). The understudied and underappreciated role of predation in the mortality of fish released from fishing gears. Fish and Fisheries, 15(3), 489-505. https://doi.org/10.1111/faf.12033

Rahman, M. M., Kelley, J. L., \& Evans, J. P. (2013). Conditiondependent expression of pre-and postcopulatory sexual traits in guppies. Ecology and evolution, 3(7), 2197-2213. https://doi.org/10.1002/ece3.632

Rahman, M.M., Gasparini, C., Turchini, G.M. \& Evans, J.P. (2014). Experimental reduction in dietary omega-3 polyunsaturated fatty acids depresses sperm competitiveness. Biology Letters, 10(3): 20140623. https://doi.org/10.1098/rsbl.2014.0623

Rahman, M.M., Pinkey, I.A., Ferthous, J., Arafat, S.T., Rahman, S.M., Asaduzzaman, M., Rahman, M.M. \& Rouf, M.A. (2020). Modulation of phenotypic traits under different rearing temperatures: Experimental evidence in male guppy (Poecilia reticulata). International Journal of Aquatic Biology, 8 (5), 344-364. https://doi.org/10.22034/ijab.v8i5.856

Reznick, D., \& Endler, J. A. (1982). The impact of predation on life history evolution in Trinidadian guppies (Poecilia reticulata). Evolution, 36(1), 160-177. https://doi.org/10.1111/j.1558-5646.1982.tb05021.x

Ruell, E., Handelsman, C., Hawkins, C., Sofaer, H., Ghalambor, C., \& Angeloni, L. (2013). Fear, food and sexual ornamentation: plasticity of colour development in Trinidadian guppies. Proceedings of the Royal Society $B$ : Biological Sciences, 280(1758), 20122019. https://doi.org/10.1098/rspb.2012.2019

Schmidt, J. M., Sebastian, P., Wilder, S. M., \& Rypstra, A. L. (2012). The nutritional content of prey affects the foraging of a generalist arthropod predator. PloS one, 7(11). https://doi.org/10.1371/journal.pone.0049223

Schmitz, O. (2017). Predator and prey functional traits: understanding the adaptive machinery driving predatorprey interactions. F1000Research, 6 . https://dx.doi.org/10.12688\%2Ff1000research.11813.1

Šmejkal, M., Baran, R., Blabolil, P., Vejř́ik, L., Prchalová, M., Bartoň, D., Mrkvička, T., \& Kubečka, J. (2017). Early lifehistory predator-prey reversal in two cyprinid fishes. Scientific reports, 7(1), 1-8. https://doi.org/10.1038/s41598-017-07339-w

Svanbäck, R., Zha, Y., Brönmark, C., \& Johansson, F. (2017). The interaction between predation risk and food ration on behavior and morphology of Eurasian perch. Ecology and evolution, 7(20), 8567-8577. https://doi.org/10.1002/ece3.3330

Tang, Z.-H., Huang, Q., Wu, H., Kuang, L., \& Fu, S.-J. (2017). The 
behavioral response of prey fish to predators: the role of predator size. PeerJ, 5, e3222.

https://doi.org/10.7717/peerj.3222

Välimäki, K., \& Herczeg, G. (2012). Ontogenetic and evolutionary effects of predation and competition on nine-spined stickleback (Pungitius pungitius) body size. Journal of animal ecology, 81(4), 859-867. https://doi.org/10.1111/j.1365-2656.2012.01971.x

Van Dievel, M., Janssens, L., \& Stoks, R. (2016). Short-and longterm behavioural, physiological and stoichiometric responses to predation risk indicate chronic stress and compensatory mechanisms. Oecologia, 181(2), 347-357. https://doi.org/10.1007/s00442-015-3440-1 